\title{
Financial Contagion and Asset Pricing
}

\author{
Renée Fry-McKibbin\#, Vance L. Martin ${ }^{+}$, and Chrismin Tang* \\ \#CAMA, Crawford School of Public Policy, Australian National University \\ ${ }^{+}$Department of Economics, University of Melbourne \\ *School of Economics, La Trobe University
}

\section{April 2014}

\begin{abstract}
Asset market interconnectedness can give rise to significant contagion risks during periods of financial crises that extend beyond the risks associated with changes in volatilities and correlations. These channels include the transmission of shocks operating through changes in the higher order comoments of asset returns, including changes in coskewness arising from changes in the interaction between volatility and average returns across asset markets. These additional contagion channels have nontrivial implications for the pricing of options through changes in the payoff probability structure and more generally, in the management of financial risks. The effects of incorrectly pricing risk has proved to be significant during many financial crises, including the subprime crisis from mid 2007 to mid 2008, the Great Recession beginning 2008 and the European debt crisis from 2010. Using an exchange options model, the effects of changes in the comoments of asset returns across asset markets are investigated with special emphasis given to understanding the effects on hedging risk during financial crises. The results reveal that by not correctly pricing the risks arising from higher order moments during financial crises, there is significant mispricing of options, while hedged portfolios during noncrisis periods become exposed to price movements in times of crises.
\end{abstract}

Keywords: Financial crises, Contagion, Exchange Options, Delta Hedging JEL Classification: C51, G15

*We would like to thank the referee for providing insightful comments on a previous version of the paper. Author contact details are: Fry-McKibbin: renee.mckibbin@anu.edu.au; Martin: vance@unimelb.edu.au; Tang: chrismin.tang@latrobe.edu.au. The authors gratefully acknowledge Australian Research Council Grant DP0985783. 


\section{Introduction}

The subprime financial crisis of 2007-2008, immediately followed by the Great Recession in mid 2008, and more recently the European debt crisis beginning 2010, reveal significant risks that arise from the interconnectedness of asset markets in the global financial landscape. The magnitude of shock transmissions from one market to others often far exceed expectations based on normal market linkages and dependence structures between assets (Dungey, Fry, González-Hermosillo and Martin (2010)). Not only do the codependence structures across financial markets change dramatically during periods of financial turbulence, these changes often extend beyond the usual changes in market correlation, and include additional crisis transmission channels operating through higher order comoments of asset returns (Fry, Martin and Tang (2010)).

The effect of changes in the comoments of asset returns on recent financial crises are highlighted in Tables 1 and 2. Table 1 provides the descriptive statistics on the first three moments of equity returns for five European countries and the US over four periods: a noncrisis period (January 3, 2006 to July 25, 2007), and three crisis periods consisting of the subprime crisis (July 26, 2007 to September 14, 2008), the Great Recession (September 15, 2008 to December 31, 2012) and the European debt crisis (January 1, 2010 to August 30, 2012) compared to the noncrisis period. All six countries are characterized by falls in average returns and increases in volatility during each crisis. Skewness also increases during the crisis periods, changing from negative skewness in the noncrisis period for equity returns of all six countries to either positive skewness or smaller negative skewness. Table 2 shows that similar results occur

for coskewness between pairs of equity returns of countries, with coskewness changing from being negative in the noncrisis period to being either positive or a smaller negative coskewness in the crisis periods. The only exception is in Table 2 where coskewness between the US and Greece (last block of the table) becomes more negative during the Great Recession, changing from -0.181 to -0.238 . 
Table 1:

Descriptive statistics on daily equity returns of selected countries for noncrisis and crisis periods: noncrisis (Jan. 3, 2006-Jul. 25, 2007); subprime crisis (Jul. 26, 2007-Sep. 14, 2008); Great Recession (Sep. 15, 2008-Dec. 31, 2012); European debt crisis (Jan. 1, 2010-Aug. 30, 2012).

\begin{tabular}{|c|c|c|c|c|c|}
\hline & & Noncrisis & Subprime & Great Recession & European Debt \\
\hline \multirow[t]{3}{*}{ France } & Mean & 0.087 & -0.089 & -0.025 & -0.042 \\
\hline & Std dev. & 1.010 & 1.593 & 2.887 & 2.017 \\
\hline & Skewness & -0.312 & -0.200 & 0.177 & 0.058 \\
\hline \multirow[t]{3}{*}{ Germany } & Mean & 0.131 & -0.086 & -0.019 & 0.034 \\
\hline & Std dev. & 1.203 & 1.808 & 2.934 & 1.938 \\
\hline & Skewness & -0.610 & -0.120 & 0.027 & -0.201 \\
\hline \multirow[t]{3}{*}{ Greece } & Mean & 0.117 & -0.153 & -0.099 & -0.200 \\
\hline & Std dev. & 1.196 & 1.707 & 2.896 & 2.626 \\
\hline & Skewness & -0.479 & 0.049 & -0.202 & 0.388 \\
\hline \multirow[t]{3}{*}{ Italy } & Mean & 0.066 & -0.109 & -0.055 & -0.085 \\
\hline & Std dev. & 0.943 & 1.428 & 2.980 & 2.314 \\
\hline & Skewness & -0.345 & -0.191 & 0.092 & -0.035 \\
\hline \multirow[t]{3}{*}{ Spain } & Mean & 0.117 & -0.079 & 0.017 & -0.093 \\
\hline & Std dev. & 0.968 & 1.639 & 2.759 & 2.272 \\
\hline & Skewness & -0.312 & -0.264 & 0.026 & 0.279 \\
\hline \multirow[t]{3}{*}{ US } & Mean & 0.062 & -0.063 & -0.027 & 0.032 \\
\hline & Std dev. & 0.629 & 1.235 & 2.246 & 1.070 \\
\hline & Skewness & -0.545 & -0.040 & 0.111 & -0.410 \\
\hline
\end{tabular}


Table 2:

Coskewness statistics of daily equity returns for noncrisis and crisis periods: noncrisis (Jan. 3, 2006-Jul. 25, 2007); subprime crisis (Jul. 26, 2007-Sep. 14, 2008); Great Recession (Sep. 15, 2008-Dec. 31, 2012); European debt crisis (Jan. 1, 2010-Aug. 30, 2012). Coskewness is calculated using $r_{1, t} r_{2, t}^{2}$. The first row of each block of the table corresponds to asset 1 and the following rows correspond to asset 2 .

\begin{tabular}{lcccc}
\hline \hline & Noncrisis & Subprime & Great Recession & European Debt \\
\hline France $(i=1)$ & & & & \\
Germany & -0.445 & -0.086 & 0.046 & -0.109 \\
Greece & -0.203 & -0.008 & -0.016 & 0.120 \\
Italy & -0.320 & -0.178 & 0.127 & 0.007 \\
Spain & -0.303 & -0.243 & 0.110 & 0.203 \\
US & -0.255 & -0.119 & -0.140 & -0.208 \\
Germany $(i=1)$ & & & & \\
France & -0.355 & -0.118 & 0.094 & -0.027 \\
Greece & -0.366 & -0.065 & -0.067 & 0.070 \\
Italy & -0.376 & -0.136 & 0.063 & -0.044 \\
Spain & -0.381 & -0.178 & 0.049 & 0.122 \\
US & -0.328 & -0.116 & -0.159 & -0.265 \\
Greece $(i=1)$ & & & & \\
France & -0.168 & -0.120 & 0.040 & 0.035 \\
Germany & -0.423 & -0.130 & 0.006 & -0.076 \\
Italy & -0.203 & -0.198 & 0.066 & 0.042 \\
Spain & -0.243 & -0.139 & -0.012 & 0.194 \\
US & -0.296 & -0.049 & -0.217 & -0.127 \\
Italy $(i=1)$ & & & & \\
France & -0.313 & -0.197 & 0.152 & 0.037 \\
Germany & -0.472 & -0.098 & 0.045 & -0.089 \\
Greece & -0.261 & -0.087 & -0.005 & 0.136 \\
Spain & -0.299 & -0.216 & 0.111 & 0.176 \\
US & -0.313 & -0.083 & -0.173 & -0.177 \\
Spain $(i=1)$ & & & & \\
France & -0.303 & -0.218 & 0.157 & 0.132 \\
Germany & -0.467 & -0.106 & 0.047 & -0.015 \\
Greece & -0.274 & 0.013 & -0.064 & 0.207 \\
Italy & -0.310 & -0.173 & 0.126 & 0.073 \\
US & -0.299 & -0.058 & -0.183 & -0.117 \\
US $(i=1)$ & & & & \\
France & -0.200 & 0.089 & 0.001 & -0.030 \\
Germany & -0.216 & -0.068 & -0.062 & -0.146 \\
Greece & -0.181 & 0.237 & -0.238 & 0.095 \\
Italy & -0.233 & 0.154 & 0.031 & -0.052 \\
Spain & -0.243 & 0.089 & -0.127 & 0.079 \\
\hline & & & &
\end{tabular}


As the statistics in Tables 1 and 2 allude, asset mispricing can be particularly significant during periods of financial crisis and contagion and that this has important implications for market participants engaged in the hedging of financial risks and for financial regulators seeking to manage risks across the financial institutions. This is particularly the case for exchange option contracts written on two or more assets where changes in the dependence structure of the underlying assets have a direct impact on the price of the option. Significant risk exposures to changes in higher order moments remain if hedging strategies are formulated using the standard Black-Scholes model that invokes multivariate normality.

To investigate the effects of contagion during financial crises on alternative hedging strategies, an exchange options model is developed following Fry, Martin and Tang (2010) which extends the usual Black-Scholes assumption of lognormal prices of the underlying assets that an option is written on, to a more general distribution that allows for the effects of higher order moments as well as comoments arising from coskewness (see also Lim, Lye, Martin and Martin (1998), Martin, Forbes and Martin (2003) and Lim, Martin and Martin (2006) in the case of non-exotic options). Special attention is given to identifying the size of mispricing from higher order comoments of asset returns during the crisis periods and how it impacts upon hedging strategies. The key results of the analysis reveal significant mispricing of options during financial crises from not pricing the risks associated with higher order moments. The analysis also shows that portfolios that are hedged against price movements during noncrisis periods become exposed to unfavorable price movements during periods of crises.

The adoption of a generalized normal distribution to capture higher order codependence in asset returns represents a natural choice as Fry, Martin and Tang (2010) show that Lagrange multiplier tests of contagion can be derived which relate to existing tests of comoments such as coskewness. An alternative approach to capture higher order dependence is based on using copulas (Patton (2006), Rodriguez (2007), Harvey (2010) 
and Busetti and Harvey (2011)). This approach is also adopted by Martin and Wang (2013) who propose a nonparametric test of contagion. Earlier approaches, especially in the context of modelling options in the presence of nonnormal asset returns, consist of the lognormal mixture model of Melick and Thomas (1997); the Edgeworth expansion of Jarrow and Rudd (1982) and Corrado and Su (1997); the Hermite polynomial approximation of Ane (1999); the nonparametric density estimator of Aït-Sahalia, Wang and Yared (2001); and the neural network approach of Garcia and Gencay (2000).

In addition to the above, there are a range of methods focussing on the importance of transmission channels of contagion operating in higher order moments or crisis measurement through extreme value methods. Usually these are in applications which are not focussed on options, however are worth mentioning here. Most of these methods use the information in the extreme (crisis) periods in subtly different ways to understand crises and contagion. Dungey, Fry, González-Hermosillo and Martin (2010) provide a summary of the key methods. For example, Favero and Giavazzi (2002) and Pesaran and Pick (2007) test for contagion in the outliers of asset returns; Bae, Karolyi and Stulz (2003) propose a coexceedance test based on a multinomial logit model; whereas Aït-Sahalia, Cacho-Diaz and Laeven (2010) allow for mutual jumps using a Hawkes process. Others use extreme value measures either to forecast crisis events such as in the early warning system literature of Frankel and Rose (1996), Kaminsky and Reinhart (1999) and more recently by Lo Duca and Peltonen (2013), or to detect a state of crisis such as the exchange market pressure index of Eichengreen, Rose and Wyplosz (1995, 1996) and extensions thereof. Related literature is by Diebold and Yilmaz (2009) who identify changes in the connectedness of asset markets during financial crises.

The rest of the paper proceeds as follows. Section 2 sets out an exchange option contract where the bivariate generalized normal distribution is specified to allow for contagious channels operating through higher order moments and comoments during periods of financial crises. To investigate the effects of these additional channels of 
contagion on exchange options, a bivariate generalized lognormal distribution is introduced to model the joint stochastic behavior of the underlying asset prices at the time the option contract matures. The results show that changes in coskewness can change the mass of the joint probability distribution of prices, resulting in changes in the probabilities of the payoffs and, in turn, the price of the options. The analysis is extended in Section 3 where the effects on hedging strategies are discussed in the presence of contagion during financial crises. Concluding comments and implications for portfolio management during financial crises are provided in Section 4.

\section{Option Pricing During Financial Crises and Con- tagion}

This section investigates the effects of contagion during financial crises on the price of exchange options between two assets, where an additional crisis transmission channel between assets exists that operates through higher order comoments of asset returns. An exchange option provides the right to exchange one asset for another asset (Magrabe (1978)). Consider an European exchange option which gives the holder the right to exchange asset 2 for asset 1 when the contract expires at time $T$. The price at time $t$ of an exchange option $\left(C_{t}\right)$ is given by the expected value of its discounted payoff

$$
C_{t}=\exp \left[-r_{f}(T-t)\right] E_{t}\left[\operatorname{Max}\left(P_{1, T}-P_{2, T}, 0\right) \mid s_{t+1}\right]
$$

where the option contract is written in terms of exchanging asset 2 for asset $1, P_{1, T}$ and $P_{2, T}$ are the respective prices of assets 1 and 2 at maturity and $r_{f}$ is the risk-free rate of interest. The operator $E_{t}[$.$] represents the conditional expectations based on$ information at time $t$ and the states of nature $s_{t+1}$.

The exchange option price formulation is similar to a call option written on asset 1 ,

only that the strike price is stochastic and depends directly on the price of asset 2 . The value of the exchange option depends on the spread between the asset prices of 1 and 2. As the ratio of asset prices $P_{1} / P_{2}$ falls, the value of holding an exchange option falls. 
The holder of the exchange option is betting that the price of asset 1 will rise relative to 2. The opposite is true for the seller of the exchange option who is obligated to give up asset 1 in exchange for asset 2 from the option holder if the option is exercised.

For the Black-Scholes option price model, asset prices are assumed to follow geometric Brownian motion. Under risk neutrality the stochastic differential equation of asset prices is specified as

$$
d P_{i}=\left(r_{f}-q_{i}\right) P_{i} d t+\sigma_{i} P_{i} d W_{i}
$$

where $q_{i}$ is the dividend yield, $\sigma_{i}$ is the instantaneous volatility of the returns on the ith asset, and $W_{i}$ is a Wiener process with the property that $d W_{i} \sim N(0, d t)$ and $E\left[d W_{i} d W_{j}\right]=\rho d t$ allows for the Wiener processes to be correlated. Given equations (1) and (2), the Black-Scholes price of the exchange option (Magrabe (1978), Hull $(2000))$, is

$$
C_{t}^{B S}=P_{1, t} \exp \left(-q_{1}(T-t)\right) N\left(d_{1}\right)-P_{2, t} \exp \left(-q_{2}(T-t)\right) N\left(d_{2}\right)
$$

where $P_{1, t}$ and $P_{2, t}$ are the underlying asset prices at time $t$, and $q_{1}$ and $q_{2}$ are the respective dividend yields which for simplicity are assumed to be constant over the life of the contract. The variables $d_{1}$ and $d_{2}$ are given by

$$
d_{1}=\frac{\ln \left(P_{1, t} / P_{2, t}\right)+\left(q_{2}-q_{1}+\sigma^{2} / 2\right)(T-t)}{\sigma \sqrt{T-t}}
$$

and

$$
d_{2}=d_{1}-\sigma \sqrt{T-t}
$$

with $N($.$) representing the cumulative probability density function of a variable that$ is normally distributed with zero mean and a standard deviation of one, and

$$
\sigma=\sqrt{\sigma_{1}^{2}+\sigma_{2}^{2}-2 \rho \sigma_{1} \sigma_{2}}
$$

where $\sigma_{1}$ and $\sigma_{2}$ are the associated volatilities of the returns of assets 1 and 2 respectively and $\rho$ measures the correlation between the two assets. 
To focus on the higher order comoments of asset returns underlying the exchange options contract, the normality assumption of asset returns as embodied in the Wiener process in the Black-Scholes framework is extended by specifying the following generalized normal distribution (Fry, Martin and Tang (2010)) ${ }^{1}$

$$
\begin{array}{r}
f\left(r_{1, t}, r_{2, t}\right)=\exp \left[\theta_{1} r_{1, t}^{2}+\theta_{2} r_{2, t}^{2}+\theta_{3} r_{1, t} r_{2, t}+\theta_{4} r_{1, t}^{3}+\theta_{5} r_{1, t}^{2} r_{2, t}\right. \\
\left.+\theta_{6} r_{1, t} r_{2, t}^{2}+\theta_{7} r_{2, t}^{3}+\theta_{8} r_{1, t}^{4}+\theta_{9} r_{2, t}^{4}-\eta\right]
\end{array}
$$

where

$$
r_{i, t}=\ln P_{i, t}-\ln P_{i, t-1}
$$

is the log-return at time $t$ on the $i^{\text {th }}$ asset, $\eta$ is the normalizing constant with the property

$$
\iint f\left(r_{1}, r_{2}\right) d r_{1} d r_{2}=1
$$

and $\theta_{i}, i=1,2 \cdots, 9$, are parameters. An important special case of the generalized normal distribution in equation (7) is that it contains the bivariate normal distribution as a special case when the following restrictions are imposed

$$
\theta_{1}=-\frac{0.5}{1-\rho^{2}}, \quad \theta_{2}=-\frac{0.5}{1-\rho^{2}}, \quad \theta_{3}=\frac{\rho}{1-\rho^{2}}, \quad \theta_{i}=0, \forall i \geqslant 4,
$$

where $\rho$ represents the correlation parameter between $r_{1}$ and $r_{2}$. Reflecting the statistical features of asset prices during financial crises summarized in Table 2, the parameters $\theta_{4}$ and $\theta_{7}$ allow for skewness in the returns of assets 1 and 2 respectively, whereas the parameters $\theta_{8}$ and $\theta_{9}$ allow for kurtosis in assets 1 and 2 respectively. Coskewess is captured by the parameters $\theta_{5}$ and $\theta_{6}$. The first form of coskewness as represented by the term $r_{1, t}^{2} r_{2, t}$, captures the interaction effect between the volatility of returns in asset 1 and the mean in asset 2, while the second form of coskewness as represented by the term $r_{1, t} r_{2, t}^{2}$, is the reverse, capturing the interaction effect between the mean

\footnotetext{
${ }^{1}$ The bivariate generalized normal distribution is an extension of the generalized normal distribution investigated by Lye and Martin (1993).
} 
of returns in asset 1 and the volatility in asset $2 .^{2}$

To highlight the effects of coskewness on the relationship between the mean and variance of returns, Figure 1 provides a 3-D plot of the trade-off between the mean of $r_{2, t}$ and the variance of $r_{1, t}$ for different levels of coskewness in the case of $r_{1, t}^{2} r_{2, t}$. The choice of parameters in (7) are

$$
\begin{gathered}
\theta_{1}=-\frac{0.5}{1-\rho^{2}}, \quad \theta_{2}=-\frac{0.5}{1-\rho^{2}}, \quad \theta_{3}=\frac{\rho}{1-\rho^{2}}, \quad \theta_{4}=0.0, \\
\theta_{5}=\{-1,-0.9, \cdots, 1.0\}, \quad \theta_{6}=\theta_{7}=0, \quad \theta_{8}=\theta_{9}=-0.25, \quad \rho=0.5 .
\end{gathered}
$$

The means, variances and coskewness are computed respectively as ${ }^{3}$

$$
\begin{aligned}
\mu_{1} & =\int_{-\infty}^{\infty} \int_{-\infty}^{\infty} r_{1, t} f\left(r_{1, t}, r_{2, t}\right) d r_{1, t} d r_{2, t}, \\
\mu_{2} & =\int_{-\infty}^{\infty} \int_{-\infty}^{\infty} r_{2, t} f\left(r_{1, t}, r_{2, t}\right) d r_{1, t} d r_{2, t}, \\
\sigma_{1}^{2} & =\int_{-\infty}^{\infty} \int_{-\infty}^{\infty}\left(r_{1, t}-\mu_{1}\right)^{2} f\left(r_{1, t}, r_{2, t}\right) d r_{1, t} d r_{2, t}, \\
\sigma_{2}^{2} & =\int_{-\infty}^{\infty} \int_{-\infty}^{\infty}\left(r_{2, t}-\mu_{2}\right)^{2} f\left(r_{1, t}, r_{2, t}\right) d r_{1, t} d r_{2, t}, \\
C K & =\int_{-\infty}^{\infty} \int_{-\infty}^{\infty}\left(r_{1, t}-\mu_{1}\right)^{2}\left(r_{2, t}-\mu_{2}\right) f\left(r_{1, t}, r_{2, t}\right) d r_{1, t} d r_{2, t} .
\end{aligned}
$$

Figure 1 shows that a decrease in positive coskewness corresponds to simultaneous falls in the risk of asset 1 and the expected return on asset 2. A switch from positive coskewness to negative coskewness corresponds to larger negative expected returns for asset 2 and increasing risk for asset 1. This trade-off between the risk and return across asset markets is comparable to the Engle-Ng news impact curve where increases in volatility are associated with increases in the absolute size of shocks, but within the same market.

\footnotetext{
${ }^{2}$ To allow for cokurtosis in the generalized normal distribution given in equation (7) the terms $r_{1} r_{2}^{3}$, $r_{1}^{2} r_{2}^{2}$ and $r_{1}^{3} r_{2}$ can also be included.

${ }^{3}$ The details of computing the integrals are discussed in the next subsection.
} 


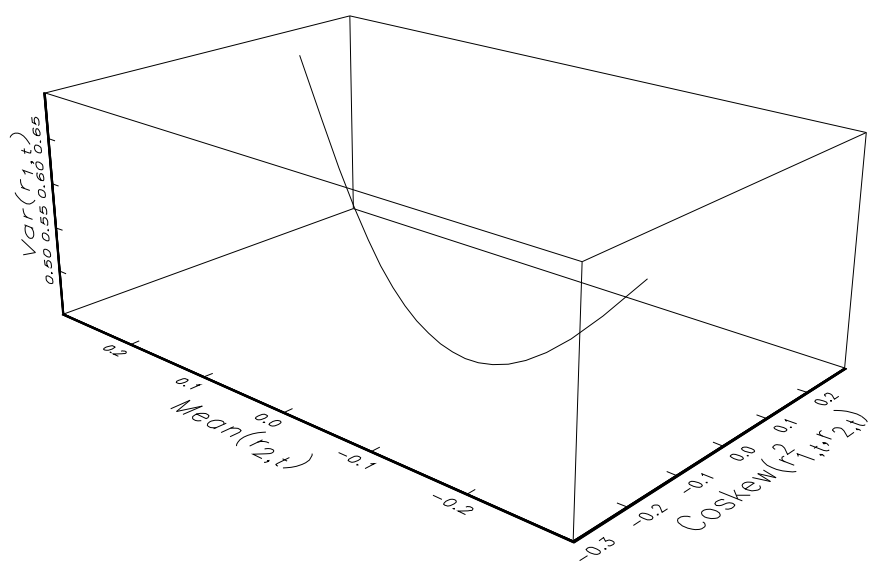

Figure 1: Trade-off between the mean of $r_{2, t}$ and the variance of $r_{1, t}$ for different levels of coskewness in the case of $r_{1, t}^{2} r_{2, t}$. Based on the parameterization in (11).

\subsection{The Bivariate Generalized Lognormal Distribution}

In pricing options what is of interest is the joint distribution of prices over the life of the exchange options contract. Given the returns distribution in (7), the price distribution conditional on lagged prices is obtained by using the transformation of variable technique

$$
g\left(P_{1, t}, P_{2, t} \mid P_{1, t-1}, P_{2, t-1}\right)=|J| f\left(\ln P_{1, t}-\ln P_{1, t-1}, \ln P_{2, t}-\ln P_{2, t-1}\right)
$$

where

$$
|J|=\left|\frac{1}{P_{1, t} P_{2, t}}\right|
$$

is the absolute value of the Jacobian using the transformation in (8). Using this expression for the Jacobian in (12), the bivariate distribution of prices conditional on 
lagged prices is then given by

$$
\begin{aligned}
g\left(P_{1, t}, P_{2, t} \mid P_{1, t-1}, P_{2, t-1}\right)= & \exp \left[\theta_{1}\left(\ln P_{1, t}-\ln P_{1, t-1}\right)^{2}+\theta_{2}\left(\ln P_{2, t}-\ln P_{2, t-1}\right)^{2}\right. \\
& +\theta_{3}\left(\ln P_{1, t}-\ln P_{1, t-1}\right)\left(\ln P_{2, t}-\ln P_{2, t-1}\right) \\
& +\theta_{4}\left(\ln P_{1, t}-\ln P_{1, t-1}\right)^{3} \\
& +\theta_{5}\left(\ln P_{1, t}-\ln P_{1, t-1}\right)^{2}\left(\ln P_{2, t}-\ln P_{2, t-1}\right) \\
& +\theta_{6}\left(\ln P_{1, t}-\ln P_{1, t-1}\right)\left(\ln P_{2, t}-\ln P_{2, t-1}\right)^{2} \\
& +\theta_{7}\left(\ln P_{2, t}-\ln P_{2, t-1}\right)^{3}+\theta_{8}\left(\ln P_{1, t}-\ln P_{1, t-1}\right)^{4} \\
& \left.+\theta_{9}\left(\ln P_{2, t}-\ln P_{2, t-1}\right)^{4}-\eta\right] \frac{1}{P_{1, t} P_{2, t}} .
\end{aligned}
$$

An important special case of (14) is obtained by imposing the bivariate normal restrictions in (10) as the conditional price distribution reduces to the bivariate lognormal distribution. Higher order comoments can be included in the bivariate distribution by now allowing $\theta_{i} \neq 0, i \geqslant 4$. For this reason, the conditional price distribution in (14) represents a generalized lognormal distribution.

The properties of the generalized lognormal distribution in (14) are highlighted in Figure 2 which gives both surface and contour plots for alternative parameterizations. For all parameterizations, conditioning is chosen as $\ln P_{1, t-1}=\ln P_{2, t-1}=1$, while $\rho=0$. The normalizing constant $\eta$ in (14) is computed using the procedure INTQUAD2 in Gauss 10 which evaluates a double integral by Gaussian quadrature. As a check on the numerical integrations, in the case of bivariate lognormality, the percentage error in computing the normalizing constant $\eta$ in (14) by numerical integration is around $2 \%$ for alternative values of $\sigma_{1}, \sigma_{2}$ and $\rho$, compared to the analytical expression of $\ln \left(2 \pi \sigma_{1} \sigma_{2}\left(1-\rho^{2}\right)^{0.5}\right)$.

The bivariate lognormal distribution given in Figures 2(a) and 2(b) is generated by imposing the restrictions in (10). As $\rho=0$, the two prices, $P_{1, t}$ and $P_{2, t}$, are independently distributed with the joint distribution exhibiting a single peak. In the context of exchange options whereby the contract is only exercised when $P_{1, T}>P_{2, T}$, 
the pertinent area of the probability space in Figure 2 is represented by the area below a $45^{0}$ line in the contour diagrams.

Resetting the parameters that control the highest even moments to $\theta_{8}=\theta_{9}=$ -0.25 , while still using the same parameter values for $\theta_{1}, \theta_{2}$ and $\theta_{3}$, results in a more peaked joint price distribution in Figures 2(c) and 2(d). The effects of coskewness are highlighted in the remaining plots in Figure 2 by changing the value of $\theta_{5}$, while imposing the restrictions of the following

$$
\theta_{1}=\theta_{2}=-0.5, \quad \theta_{3}=0.0, \quad \theta_{4}=0.0, \quad \theta_{6}=\theta_{7}=0, \quad \theta_{8}=\theta_{9}=-0.25
$$

In Figures 2(e) and 2(f), the coskewness parameter is $\theta_{5}=-0.5$ which has the effect of stretching the distribution in the direction of $P_{1, t}$ resulting in the distribution of $P_{1, t}$ conditional on $P_{2, t}$ exhibiting longer tails especially where conditioning corresponds to relatively lower values of $P_{2, t}$. This result occurs because for relatively low values of $P_{2, t}$, the "mean" part of the coskewness term given by $\ln P_{2, t}-\ln P_{2, t-1}$, is negative by definition. Combining this with the fact that $\theta_{5}<0$, shows that for relatively low values of $P_{2, t}$, the sign on the "variance" part of the coskewness term given by $\left(\ln P_{1, t}-\ln P_{1, t-1}\right)^{2}$, is positive. As $\left(\ln P_{1, t}-\ln P_{1, t-1}\right)^{2}>0$ for all values of $P_{1, t}$, the joint price distribution is stretched in the direction of $P_{1, t}$. By changing the coskewness parameter to $\theta_{5}=-0.8$, Figures $2(\mathrm{~g})$ and $2(\mathrm{~h})$ show that there is even more stretching of the joint price distribution in the direction of $P_{1, t}$.

In Figures 2(i) and 2(j), the coskewness parameter is set at $\theta_{5}=0.5$, which is increased to $\theta_{5}=0.8$ in Figures $2(\mathrm{k})$ and $2(\mathrm{l})$. In these two cases, there is now stretching in the $P_{2, t}$ direction for relatively low values of $P_{1, t}$. This arises because for relatively "large" values of $P_{2, t}$, the "mean" part of the coskewness term given by $\ln P_{2, t}-\ln P_{2, t-1}$, is positive and when combined with $\theta_{5}>0$ and $\left(\ln P_{1, t}-\ln P_{1, t-1}\right)^{2}>0$, the net effect is a positive effect on the joint price distribution in the direction of $P_{2, t}$. 

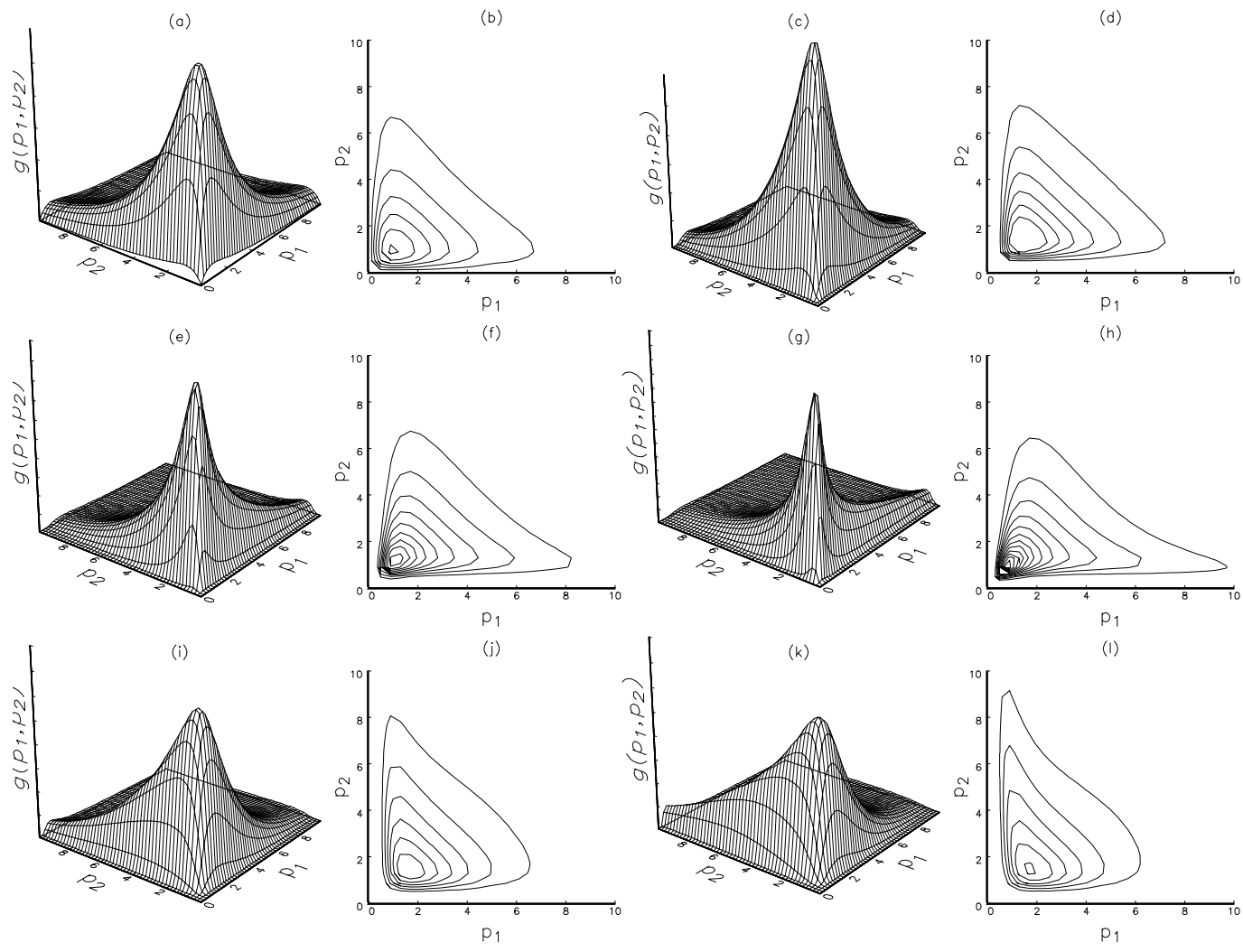

Figure 2: Generalized joint lognormal price distributions, as given in equation (14).

\begin{tabular}{|rrrrrrrrrr|}
\hline & $\theta_{1}$ & $\theta_{2}$ & $\theta_{3}$ & $\theta_{4}$ & $\theta_{5}$ & $\theta_{6}$ & $\theta_{7}$ & $\theta_{8}$ & $\theta_{9}$ \\
$\mathrm{a}, \mathrm{b}$ & -0.5 & -0.5 & 0.0 & 0.0 & 0.0 & 0.0 & 0.0 & 0.0 & 0.0 \\
$\mathrm{c}, \mathrm{d}$ & -0.5 & -0.5 & 0.0 & 0.0 & 0.0 & 0.0 & 0.0 & -0.25 & -0.25 \\
$\mathrm{e}, \mathrm{f}$ & -0.5 & -0.5 & 0.0 & 0.0 & -0.5 & 0.0 & 0.0 & -0.25 & -0.25 \\
$\mathrm{~g}, \mathrm{~h}$ & -0.5 & -0.5 & 0.0 & 0.0 & -0.8 & 0.0 & 0.0 & -0.25 & -0.25 \\
$\mathrm{i}, \mathrm{j}$ & -0.5 & -0.5 & 0.0 & 0.0 & 0.5 & 0.0 & 0.0 & -0.25 & -0.25 \\
$\mathrm{k}, \mathrm{l}$ & -0.5 & -0.5 & 0.0 & 0.0 & 0.8 & 0.0 & 0.0 & -0.25 & -0.25 \\
\hline
\end{tabular}




\subsection{The Effects on Exchange Options of Coskewness in the Expiration Distribution}

There are two natural ways that the generalized bivariate lognormal price distribution can be introduced into the exchange options model. The first is through the generating process of the joint distribution of returns on the two assets over the life of the exchange option contract and the second is through the specification of the joint price distribution at the time of maturity, namely for $P_{1, T}$ and $P_{2, T}$ where $T$ is the maturity date of the contract. In this section, the latter is discussed with special emphasis on the effects of coskewness on the terminal distribution and the corresponding effects on the price of the exchange option contract written at time $t$. The former case is discussed in the following section.

Consider the following bivariate generalized lognormal (conditional) distribution corresponding to the prices at maturity

$$
\begin{aligned}
g\left(P_{1, T}, P_{2, T} \mid P_{1, t}, P_{2, t}\right)=\exp [ & \theta_{1} z_{1}^{2}+\theta_{2} z_{2}^{2}+\theta_{3} z_{1} z_{2}+\theta_{4} z_{1}^{3}+\theta_{5} z_{1}^{2} z_{2} \\
& \left.+\theta_{6} z_{1} z_{2}^{2}+\theta_{7} z_{2}^{3}+\theta_{8} z_{1}^{4}+\theta_{9} z_{2}^{4}-\eta\right] \frac{1}{P_{1, t} P_{2, t}},
\end{aligned}
$$

where the coskewness parameters $\theta_{5}$ and $\theta_{6}$ have the values

$$
\theta_{5}=\{0,-0.8,0.8\}, \quad \theta_{6}=\{0,-0.3,0.3\},
$$

while the remaining parameters are set at

$$
\theta_{1}=-\frac{0.5}{1-\rho^{2}}, \theta_{2}=-\frac{0.5}{1-\rho^{2}}, \theta_{3}=\frac{\rho}{1-\rho^{2}}, \theta_{4}=0.0, \theta_{6}=\theta_{7}=0, \theta_{8}=\theta_{9}=-0.25 .
$$

In the case of the exchange options model, the standardized random variables $z_{1, T}$ and $z_{2, T}$, in $(15)$ are chosen as

$$
\begin{aligned}
& z_{1, T}=\frac{\ln P_{1, T}-\ln P_{1, t}-\left(r_{f}-q_{1}-0.5 \sigma_{1}^{2}\right)(T-t)}{\sigma_{1} \sqrt{(T-t)}} \\
& z_{2, T}=\frac{\ln P_{2, T}-\ln P_{2, t}-\left(r_{f}-q_{2}-0.5 \sigma_{2}^{2}\right)(T-t)}{\sigma_{2} \sqrt{(T-t)}},
\end{aligned}
$$

where all terms are as defined above. 
The price of the exchange option is then given by

$$
C_{t}^{G N}=\exp \left[-r_{f}(T-t)\right] \int_{0}^{\infty} \int_{P_{2, T}}^{\infty}\left(P_{1, T}-P_{2, T}\right) g\left(P_{1, T}, P_{2, T} \mid P_{1, t}, P_{2, t}\right) d P_{1, T} d P_{2, T},
$$

with the range of integration of $P_{1, T}$ being from $P_{2, T}$ to $\infty$, ensuring that only probabilities where

$$
P_{1, T}>P_{2, T}
$$

are considered in the evaluation of the exchange option. This choice of $z_{1, T}$ and $z_{2, T}$ in (16) is adopted as the exchange options price $C_{t}^{G N}$ is equivalent to the Black-Scholes price given in (3) under the assumption of bivariate lognormality, that is, $\theta_{i}=0$, $i \geqslant 4$. For general parameterizations of the generalized bivariate lognormal distribution $g\left(P_{1, T}, P_{2, T} \mid P_{1, t}, P_{2, t}\right)$, the evaluation of the integrals in (17) cannot be evaluated analytically as in the case of the Black-Scholes exchange option price. Instead these integrals are computed numerically using the Gaussian quadrature procedure INTGRAT2 in GAUSS 10.

As a test of the quality of the numerical integrations, the exchange option price in the case of bivariate lognormality is computed using the analytical expression in (3) and compared to two prices based on numerical integration. The first numerically integrated option price uses the analytical form of the normalizing constant of the bivariate lognormal distribution while computing the double integrals in (17) numerically. The second numerically integrated option price uses the numerical form of the normalizing constant of the bivariate lognormal distribution while still computing the double integrals in (17) numerically as well. Using as inputs into the exchange option

$$
\begin{gathered}
P_{1, t}=P_{2, t}=1, \quad q_{1}=0.04, \quad q_{2}=0.05, \quad r_{f}=0.1, \\
T-t=1, \quad \sigma_{1}=\sigma_{2}=0.2, \quad \rho=0.5,
\end{gathered}
$$

the three exchange option prices are:

$$
\begin{array}{ll}
\text { Analytical } & =0.0810264353 \\
\text { Numerical with normalizing constant evaluated analytical } & =0.0810264356 \\
\text { Numerical with normalizing constant evaluated numerical } & =0.0810208315
\end{array}
$$




\section{Table 3:}

The price of exchange options in (17) for alternative levels of coskewness in the expiration bivariate price distribution in (15). Exchange option inputs are based on

(18) with the parameters of the bivariate generalized lognormal distribution set at

$$
\theta_{1}=-\frac{0.5}{1-\rho^{2}}, \theta_{2}=-\frac{0.5}{1-\rho^{2}}, \theta_{3}=\frac{\rho}{1-\rho^{2}}, \theta_{4}=0.0, \theta_{7}=0, \theta_{8}=\theta_{9}=-0.1 .
$$

\begin{tabular}{rccc}
\hline \hline$\theta_{5}$ & Option Price, $C_{t}^{G N}$ & $\theta_{6}$ & Option Price, $C_{t}^{G N}$ \\
\hline 0.0 & 0.0673 & 0.0 & 0.0673 \\
-0.2 & 0.0708 & -0.2 & 0.0684 \\
-0.4 & 0.0731 & -0.4 & 0.0701 \\
0.2 & 0.0642 & 0.2 & 0.0663 \\
0.4 & 0.0633 & 0.4 & 0.0653 \\
\hline
\end{tabular}

The numerical price which uses the analytical expression of the normalizing constant in the bivariate lognormal distribution is accurate to the $6^{\text {th }}$ decimal place. In the case where the option price is computed with the normalizing constant $\eta$ and the double integrals in (17) both evaluated numerically, the exchange option price is accurate to the $5^{\text {th }}$ decimal place.

Table 3 gives the exchange option prices based on (17) for alternative values of the coskewness parameters $\theta_{5}$ and $\theta_{6}$, with the exchange option inputs given in (18). The effect of increasing negative coskewness by allowing for larger negative values of $\theta_{5}$, results in the joint generalized lognormal distribution stretching along the $P_{1, T}$ axis. This raises the probability of higher payoffs, $P_{1, T}-P_{2, T}$, which, in turn, leads to higher option prices. The same qualitative result occurs for increasing negative skewness through larger negative values of $\theta_{6}$. In the case of positive coskewness, through either positive increases in $\theta_{5}$ or $\theta_{6}$, the mass of the joint distribution now moves in the direction of $P_{2, T}$ with the joint distribution stretching along the $P_{2, T}$ axis. This corresponds to higher probabilities of lower payoffs, resulting in lower prices for exchange options. 


\subsection{Pricing by Monte Carlo Methods}

To compute the option price in equation (1) assuming that returns at each point in time over the life of the contract from $t$ to $T$, are based on either the bivariate generalized normal distribution in (7) or the bivariate generalized lognormal distribution in (15), as an analytical solution is not available Monte Carlo methods to compute the price of the option are adopted. The steps involved consist of replacing the conditional expectation in equation (1) by simulating the asset price equation $H=10,000$ times using a discrete time step, and assuming that the disturbances are drawn from the generalized normal distribution in equation (7). The option price is then computed as the discounted payoff of the sample mean of the simulation runs

$$
C_{t}^{G N}=\exp \left[-r_{f}(T-t)\right] \frac{1}{H} \sum_{i=1}^{H} \operatorname{Max}\left(P_{1, T}^{i}-P_{2, T}^{i}, 0\right) .
$$

To improve the accuracy of the simulated option price, a control variate is used by augmenting the generalized normal distribution option price in equation (19) by the difference between the analytical Black-Scholes price and the Monte Carlo price based on bivariate normality.

To determine the effects of contagion during a financial crisis on the price of exchange options, a simulation experiment is conducted. As a benchmark, the price of exchange options during the noncrisis period are assumed to correspond to the BlackScholes prices whereby the Weiner processes of the two underlying assets the exchange option contract is written on, follow a bivariate normal distribution. The exchange option prices are evaluated using the following inputs

$$
\begin{gathered}
q_{1}=0.04, \quad q_{2}=0.05, \quad r_{f}=0.1, \\
T-t=1, \quad \sigma_{1}=\sigma_{2}=0.2, \quad \rho=0.5,
\end{gathered}
$$

with the prices of asset 1 and asset 2 at time $t$ taking on values between 60 and 100 in increments of 5

$$
P_{1, t}=\{60,65, \ldots, 95,100\}, \quad P_{2, t}=\{60,65, \ldots, 95,100\}
$$


During the period of the financial crisis, additional contagious channels arise through the higher order moments by assuming that the disturbances of the prices of the underlying assets follow a generalized normal distribution. To determine the potential size of mispricing during the crisis period from ignoring the nonnormalities in returns, the Black-Scholes prices are also computed in the crisis period using the implied volatility and correlation of the returns based on the generalized normal distribution.

As Table 1 shows that returns during the financial crises tend to exhibit positive skewness and coskewness, the bivariate generalized normal distribution is parameterized accordingly in the simulation. The parameters of the generalized normal distribution in equation (7) during the crisis period are set to ${ }^{4}$

$$
\begin{aligned}
& \theta_{1}=\theta_{2}=-\frac{0.5}{1-\rho^{2}}, \quad \theta_{3}=\frac{\rho}{1-\rho^{2}}, \\
& \theta_{4}=0.0, \quad \theta_{5}=0.0, \quad \theta_{6}=0.7, \\
& \theta_{7}=0.0, \quad \theta_{8}=\theta_{9}=-0.1,
\end{aligned}
$$

with $\rho=0.5$, which yields positive coskewness of 0.270 during the crisis period compared to a value of zero coskewness in the noncrisis case. The noncrisis distribution of returns is represented by the standardized bivariate normal distribution with zero means, unit variances and correlation $\rho=0.5$, which is obtained by imposing the additional restrictions $\theta_{i}=0, i \geqslant 4$, on the parameters in equation (7).

To determine the potential size of mispricing during the crisis period from ignoring coskewness in returns, two exchange option prices are computed. The first is the Black-Scholes price using equation (3). In computing this price in the crisis period the

\footnotetext{
${ }^{4} \mathrm{~A}$ second simulation using an alternative form of coskewness was also conducted by specifying the parameters of the generalized normal distribution in the crisis period as

$$
\begin{aligned}
& \theta_{1}=\theta_{2}=-\frac{0.5}{1-\rho^{2}}, \quad \theta_{3}=\frac{\rho}{1-\rho^{2}}, \\
& \theta_{4}=0.0, \quad \theta_{5}=0.6, \quad \theta_{6}=0.0 \\
& \theta_{7}=0.0, \quad \theta_{8}=\theta_{9}=-0.1,
\end{aligned}
$$

with $\rho=0.5$ as before, which yields positive coskewness of 0.354 compared to a value of zero coskewness in the noncrisis case. The results change only slightly when examining the second from of coskewness. For details on that simulation see the working paper of Fry-McKibbin, Martin and Tang (2013).
} 
parameter values for volatility and correlation are taken as the implied values associated with the bivariate generalized normal returns distribution. Formally, this is achieved by computing

$$
\begin{aligned}
\sigma_{1}^{2} & =\iint\left(r_{1}-\mu_{1}\right)^{2} f\left(r_{1}, r_{2}\right) d r_{1} d r_{2}=0.964^{2} \\
\sigma_{2}^{2} & =\iint\left(r_{2}-\mu_{2}\right)^{2} f\left(r_{1}, r_{2}\right) d r_{1} d r_{2}=1.122^{2} \\
\sigma_{1,2} & =\iint\left(r_{1}-\mu_{1}\right)\left(r_{2}-\mu_{2}\right) f\left(r_{1}, r_{2}\right) d r_{1} d r_{2}=0.727
\end{aligned}
$$

where the means are computed as

$$
\mu_{i}=\iint r_{i} f\left(r_{1}, r_{2}\right) d r_{1} d r_{2}, \quad i=1,2 .
$$

The value of the correlation parameter increases from 0.5 during the noncrisis period to

$$
\rho=\frac{\sigma_{1,2}}{\sigma_{1} \sigma_{2}}=0.672,
$$

during the crisis period. The second price computed is the generalized normal exchange option price based on (19), by simulating the two asset prices 10,000 times over the life of the contract of 1 year in steps of $\Delta t=0.1$.

The results of the simulations are presented in Figure 3 with the Black-Scholes price $\left(C_{t}^{B S}\right)$ given in Figure 3(a) and the generalized normal distribution price $\left(C_{t}^{G N}\right)$ given in Figure 3(b). Inspection of the two graphs shows that option prices computed according to $C_{t}^{B S}$ during a financial crisis understate the true price as represented by 
$C_{t}^{G N}$, for all underlying asset price pairs under consideration.

(a)

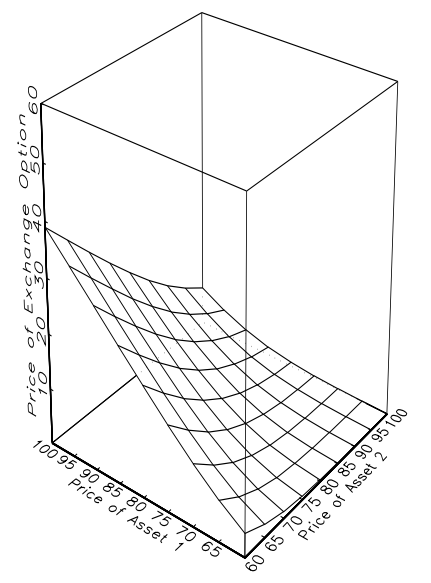

(b)

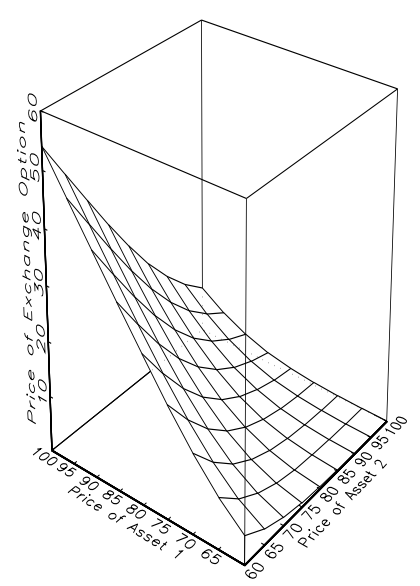

Figure 3: Option prices during a financial crisis based on the parameterizations in (21). Part (a) gives the Black-Scholes price $C_{t}^{B S}$, part (b) gives the generalized normal price $C_{t}^{G N}$.

Figure 4 shows the extent of underpricing of exchange options in absolute and percentage terms. Figure 4(a) reveals that the extent of underpricing in absolute terms becomes higher as the exchange option moves from being out-of-the-money towards being in-the-money. Inspection of the option prices generated reveals that the absolute sizes of underpricing are on average, $-0.35,-1.21$ and -5.77 , when the options are out-of-the-money, at-the-money and in-the-money respectively.

The size of underpricing in percentage terms across the various asset price pairs under consideration can be seen in Figure 4(b). On average, the exchange option price is understated by $-29.47 \%,-17.77 \%$ and $-23.00 \%$ when the options are out-of-themoney, at-the-money and in-the-money respectively. Overall, for all the underlying asset price pairs under consideration, the Black-Scholes prices in the crisis period underprice exchange options by $25.30 \%$ when compared to $C_{t}^{G N}$, the price which correctly 
allows for positive coskewness in the crisis period.

(a)

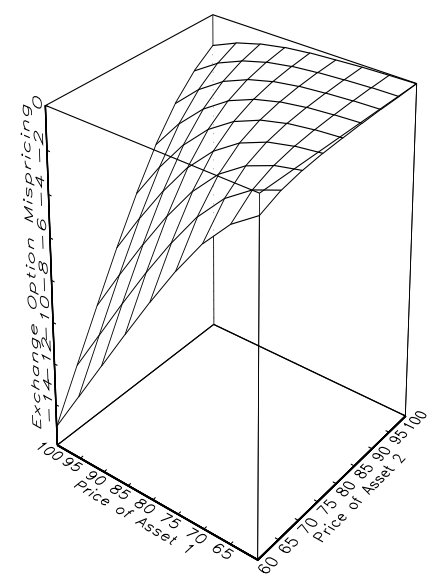

(b)

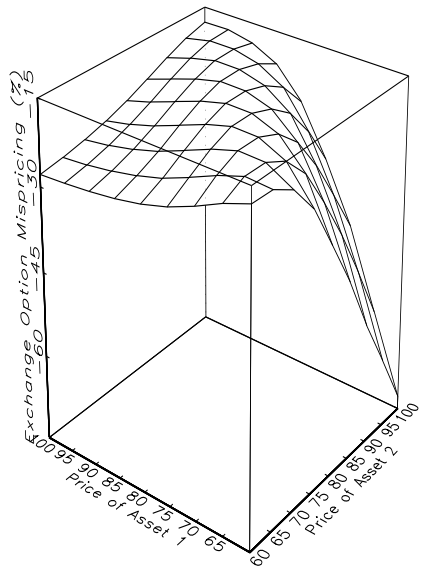

Figure 4: Mispricing error of Black-Scholes during a financial crisis, based on the parameterizations in (21). Part (a) is $C_{t}^{B S}-C_{t}^{G N}$, while part (b) gives $\left(C_{t}^{B S} / C_{t}^{G N}-1\right) \times 100$.

Figure 5 provides cross-sectional views of the exchange option prices computed using $C_{t}^{B S}$ and those generated based on $C_{t}^{G N}$, for selected prices of assets 1 and 2 . Panel (a) provides the results for price pairs for $P_{1}=\{60,80,100\}$ with $P_{2}$ ranging from 60 to 100, while panel $(b)$ is based on the price pairs for $P_{2}=\{60,80,100\}$ with $P_{1}$ ranging from 60 to 100 . For given price levels of asset 1, the size of underpricing increases as the price of asset 2 falls from 100 to 60 in Panel (a) of Figure 5. Similarly, for given price levels of asset 2, the size of underpricing increases as the price of asset 
1 rises from 60 to 100 in Panel (b) of Figure 5.

(a)

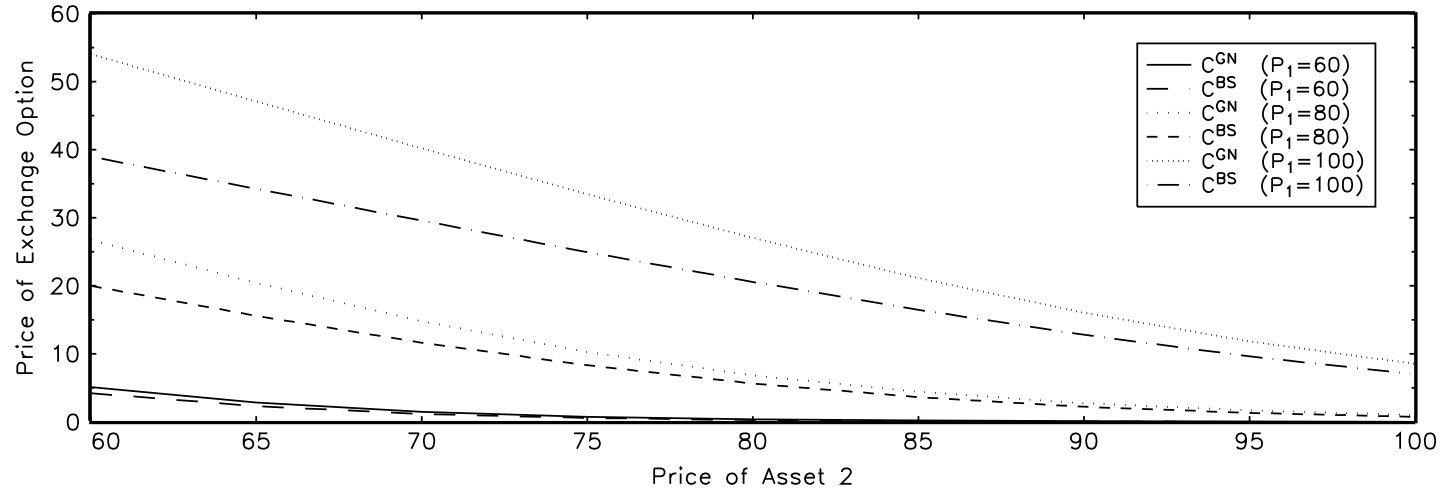

(b)

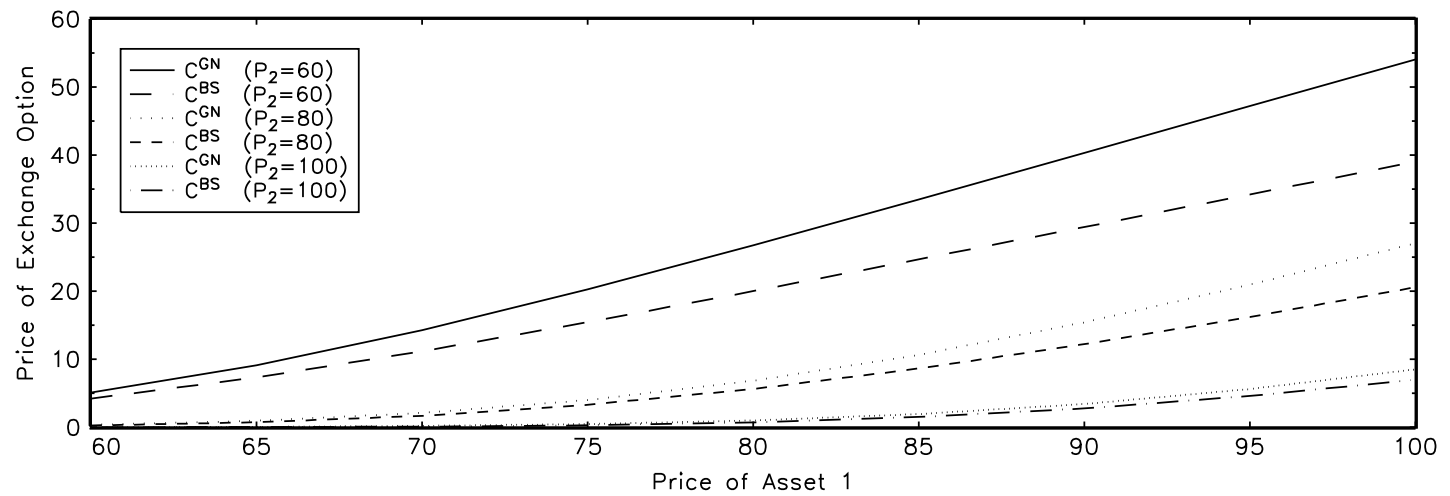

Figure 5: Exchange option prices for generalized normal $C_{t}^{G N}$ and Black-Scholes $C_{t}^{B S}$ cases corresponding to various asset price pairs based on the parameterizations in $(21)$.

\section{Portfolio Effects of Financial Crises}

The risks arising from having open positions in exchange options can be hedged. A common approach to hedging an option is delta hedging where an offsetting underlying asset position equivalent to the option face value multiplied by its current delta, is taken. For a call option, the delta is simply given as the change in the call option value with respect to a change in the asset price. When an offsetting delta equivalent position is held against an option position, the overall position is considered delta neutral. In this situation, the combined option and hedge position will show no profit or loss for small changes in the underlying asset price (see Hull, 1970). The deltas of 
the exchange option with respect to the two underlying assets can likewise be derived from the pricing equation in (3) so that offsetting positions may be taken in each of the respective assets to hedge against the underlying sources of price risks.

\subsection{Delta Hedging}

In this section, the deltas derived analytically from the Black-Scholes pricing equation in (3) are computed for a selected range of prices for the underlying assets. These deltas which are computed based on the assumption of bivariate normality are then compared to the deltas computed from numerically generated exchange option prices that take into account higher order comoments, including coskewness during the crisis period. The difference in the analytical and simulated deltas correspond to the hedging errors that may result from using the Black-Scholes option pricing equation in the presence of coskewness during periods of financial crisis and contagion. In presenting the delta results, the simulation experiments performed in the previous section are adopted again.

The deltas of the Black-Scholes exchange option with respect to the underlying assets 1 and 2, are obtained by differentiating equation (3) with respect to $P_{1, t}$ and $P_{2, t}$, the prices of the two assets (see Appendix A for details). They are given as

$$
\begin{aligned}
& \frac{\partial C^{B S}}{\partial P_{1, t}}=\exp \left(-q_{1}(T-t)\right) N\left(d_{1}\right), \\
& \frac{\partial C^{B S}}{\partial P_{2, t}}=-\exp \left(-q_{2}(T-t)\right) N\left(d_{2}\right) .
\end{aligned}
$$

In the case of the generalized normal option price in (19), the deltas need to be com-

puted numerically. Using a step interval of 1, the numerical derivatives to compute the delta for each asset are as follows

$$
\begin{aligned}
& \left.\frac{\partial C^{G N}}{\partial P_{1, t}}\right|_{P_{1}=j, P_{2}=j+k}=\left.C^{G N}\right|_{P_{1}=j+k+1, P_{2}=j+k}-\left.C^{G N}\right|_{P_{1}=j, P_{2}=j+k}, \\
& \left.\frac{\partial C^{G N}}{\partial P_{2, t}}\right|_{P_{1}=j, P_{2}=j+k}=\left.C^{G N}\right|_{P_{1}=j, P_{2}=j+k+1}-\left.C^{G N}\right|_{P_{1}=j, P_{2}=j+k}
\end{aligned}
$$


where

$$
\begin{aligned}
j & =\{60,70,80,90,100\}, \\
k & =\{-20,-15,-10,-5,0,5,10,15,20\} .
\end{aligned}
$$

Table 4 presents the deltas in (22) to (25) for various asset price pairs using the parameterization in simulation 1 given in (21). The deltas are computed for $P_{1}=$ $\{60,70,80,90,100\}$, each paired with prices of asset 2 that are higher than the level of $P_{1}$ to a maximum of 20 at increments of 5 , equal to the level of $P_{1}$ and lower than $P_{1}$ to a maximum of 20 at intervals of 5 . These scenarios correspond to the exchange option being out-of-the money, at-the money and in-the-money respectively.

The deltas corresponding to asset 1 are positive as increases in the price of the underlying asset 1 provides the holder of the exchange option with the right to exchange asset 2 for the now more valuable asset 1 . The deltas corresponding to asset 2 are negative as increases in the price of the underlying asset 2 decreases the value of the exchange option as one has to give up a now more valuable asset 2 in exchange for asset 1 in exercising the option.

As the exchange option moves from being out-of-the-money to being in-the-money, the value of delta with respect to $P_{1}$ becomes larger while the value of delta with respect to $P_{2}$ becomes more negative. This is the case for deltas based on the BlackScholes pricing equation as well as those based on the generalized normal exchange option price.

Across all asset price pairs under consideration, the positive deltas generated for the generalized normal exchange option prices are larger than the deltas based on Black-Scholes. As for the deltas of exchange options with respect to $P_{2}$, the deltas corresponding to the generalized normal option prices are consistently more negative than those based on Black-Scholes. Moreover, for certain price pairs, the delta associated with the generalized normal options are greater in absolute terms than unity. In contrast, and by construction, the deltas associated with the Black-Scholes options are 
all between 0.0 and 1.0. This result suggests that during financial crises, the incorrect adoption of Black-Scholes delta hedging may lead to an under-estimate in absolute terms of the quantities needed of the underlying assets in the portfolio.

Inspection of Figure 6 reveals that as the exchange option moves from out-of-themoney to in-the-money, the level of the differences in the deltas computed based on the generalized normal and Black-Scholes option prices, rises nonlinearly. When the exchange option is in-the-money, the level of the differences in the deltas is higher at lower values of $P_{1}$ for each given value of $P_{1}-P_{2}$. The reverse occurs when the exchange option is out-of-the-money, suggesting the presence of a level effect.

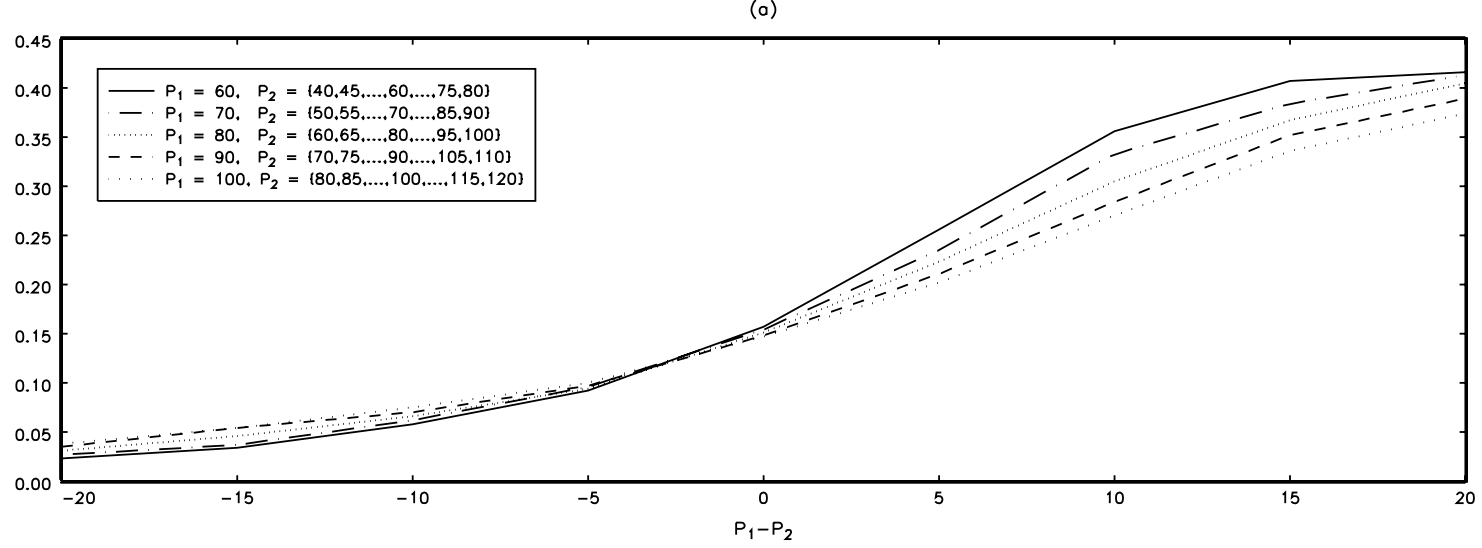

(b)

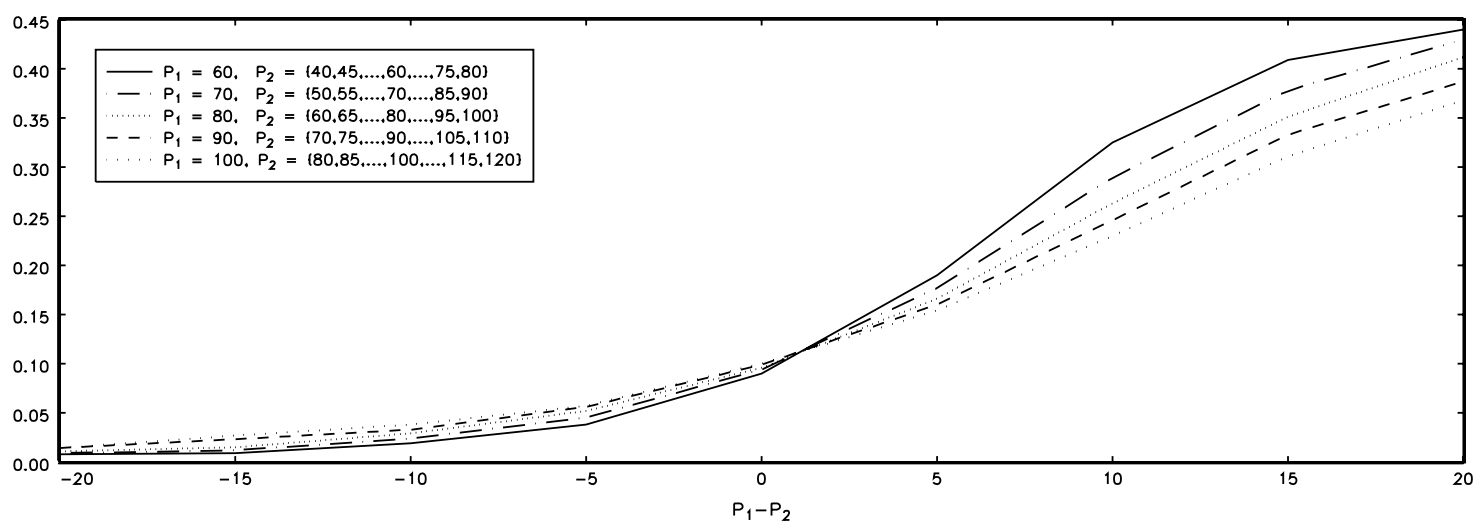

Figure 6: Differences between generalized normal and Black-Scholes deltas using the parameterization in (21). In Panel (a), the generalized normal delta is based on (24) and the Black-Scholes delta is based on (22) for asset 1. In Panel (b), the generalized normal delta is based on (25) and the Black-Scholes delta is based on (23) for asset 2.

The results for the Black-Scholes and generalized normal deltas based on the sim- 
Table 4:

Deltas corresponding to asset price pairs based on the parameterizations given in (21).

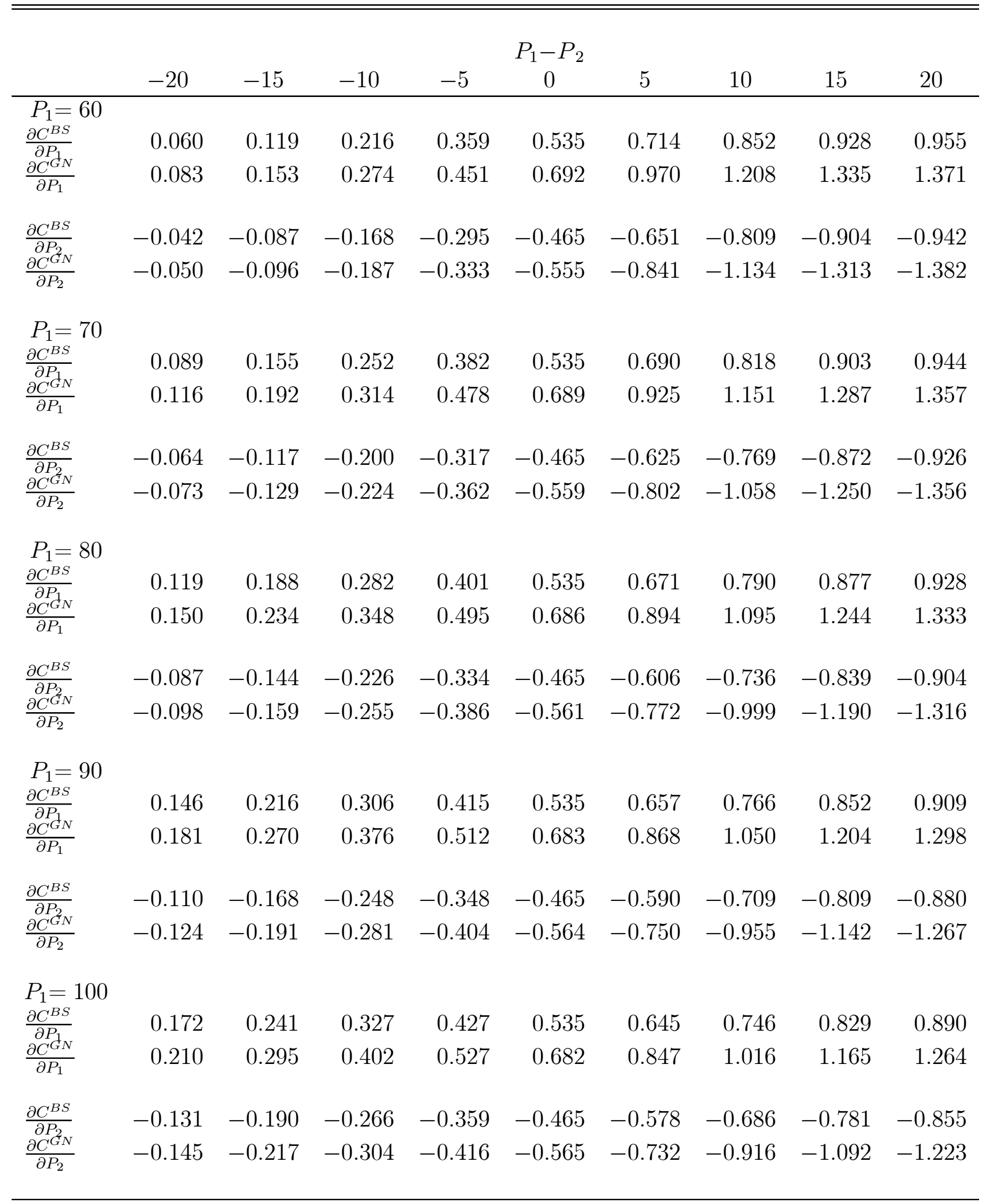


ulation in Section 2.3 as well as the second simulation presented in Fry-McKibbin, Martin and Tang (2013) using a different form of coskewness, shows that the deltas based on Black-Scholes option prices for both assets are fairly insensitive to the change in coskewness arising from the change in parameterizations across the two simulations. This is not the case for the deltas based on generalized option prices where the deltas corresponding to both assets are uniformly higher in absolute terms for both simulations. For example, for the at-the-money options with $P_{1}=P_{2}=80$, the Black-Scholes deltas are both 0.535 in the simulation and also in Fry, Martin and Tang (2013), whereas the corresponding generalized normal deltas are respectively 0.686 and 0.613 , a reduction of over $10 \% .^{5}$

\subsection{Risk-Free Hedge and Rebalancing}

By engaging in delta-hedging over the life of the exchange option, a hedge portfolio consisting of the option and positions in the underlying assets can be created to manage the risks arising from price fluctuations in the underlying assets. Assuming frequent portfolio rebalancing the return on the hedge portfolio $r_{h}$, approximates the risk free rate of return

$$
r_{h}=\frac{V_{t}}{V_{t-1}}-1 \simeq r_{f}
$$

The value of the hedge portfolio for the seller of the exchange option at time $t-1$ is $V_{t-1}$ which equals the sum of a short position in the exchange option and offsetting positions in the underlying stocks (i.e., a long position in asset 1 by the amount indicated by $\delta_{1, t-1}$, a short position in asset 2 by the amount $\delta_{2, t-1}$, with the positions in each asset multiplied by the respective prices)

$$
V_{t-1}=\delta_{1, t-1} P_{1, t-1}-\delta_{2, t-1} P_{2, t-1}-C_{t-1} .
$$

\footnotetext{
${ }^{5}$ Comparison of the Black-Scholes and the generalized normal deltas using the second form of coskewness defined in footnote 4 reveal the same qualitative patterns as the deltas reported in Figure 6 for the simulation in Section 2.3. In particular, as the exchange option moves from out-of-the-money to in-the-money, the absolute differences in the deltas computed based on the generalized normal and Black-Scholes option prices, rises nonlinearly.
} 
At time $t$ the value of this portfolio without rebalancing over the period, changes as a result of movements to the two underlying asset prices and the exchange option price is given as

$$
V_{t}=\delta_{1, t-1} P_{1, t}-\delta_{2, t-1} P_{2, t}-C_{t}
$$

The hedge portfolio is then rebalanced at time $t$ according to the changes in the values of the respective deltas for the underlying assets, so that the quantities of the positions in the two assets correspond to the updated deltas. In this way, the construction of the portfolio ensures that the return approximates the risk free at each time interval of rebalancing as the prices of the underlying assets change.

To highlight the effects of coskewness on the ability to construct a portfolio that minimizes exposure to price movements, the following experiment is undertaken where the maturity of the option is three-months and rebalancing takes place each month over the life of the option contract. Two portfolios are constructed: one based on pricing based on Black-Scholes using $C_{t}^{B S}$ in equation (3), and the other based on the generalized normal option price $C_{t}^{G N}$ using equation (17). The prices of the underlying assets are simulated from a generalized normal distribution with parameterizations consistent with the presence of coskewness during periods of financial crisis. As these prices change in each hedging period, the Black-Scholes exchange option price $C_{t}^{B S}$ is recomputed accordingly, whilst the generalized normal exchange option price is computed using Monte Carlo simulations conducted outside of the hedging programme in a separate procedure. The procedure simulates equation (1) 10,000 times, as described in Section (2.3) and computes the option price as the discounted payoff of the sample mean of these simulation runs. As the investor progresses from one hedging period to the next, a new exchange option price $C_{t}^{G N}$ is simulated, treating the option in each hedging period as a new option with a contract life reduced by the hedging time periods that have elapsed.

Using the analytical and simulated option prices and their corresponding deltas, 
the delta-hedge is rebalanced monthly throughout the life of the exchange option, with portfolio returns computed in each hedging period using (26). The portfolio returns are then averaged across the hedging periods, and then again across the 100 times that this process is repeated in the simulations. For a coskewness parameter value of $\theta_{6}=0.1$, using a time step of $d t=1 / 12$ where the option contract life is $t=13 / 52$, the simulated average return on the hedge portfolio based on $C_{t}^{B S}$ and $C_{t}^{G N}$ are $14.62 \%$ and $13.15 \%$ respectively. This compares with the $10 \%$ risk free rate of return specified in this simulation exercise which took approximately 100 hours to complete. Increasing the coskewness parameter to $\theta_{6}=0.2$, results in the returns on the two portfolios equaling $15.36 \%$ for Black-Scholes and $14.39 \%$ for the generalized normal portfolio. These results show that the construction of a portfolio based on Black-Scholes which ignores the presence of coskewness, yields a portfolio that is exposed to price movements with the degree of exposure increasing as the level of coskewness increases. By embedding coskewness into the pricing of the portfolio reduces the exposure of the portfolio with the return on the portfolio being closer to the risk free rate.

\section{Conclusions and Implications for Portfolio Man- agement}

The recent financial crises, including subprime, the Great Recession and the European debt crisis, revealed additional crisis transmission channels operating through higher order comoments of asset returns. Asset mispricing can be particularly significant during periods of financial crisis and contagion. Financial institutions which originate options such as the exchange option may engage in delta hedging in order that they earn premiums from writing the options without the accompanying risk exposures. However, if their delta hedging strategies are based on the incorrect pricing formulation that do not take into account the presence of higher order moments during periods of crisis, the potential losses can be significant, as shown in this paper. This has impor- 
tant implications for market participants engaged in the hedging of financial risks and for financial regulators seeking to manage risks across the financial institutions. Mispricing of assets during periods of financial crisis and contagion could have systematic implications for the financial stability of the economies.

The key implication of the results of the paper is the importance of pricing higher order moments, especially during financial crises. Option prices based on Black-Scholes assumptions, and in particular, multivariate normality, can result in significant mispricing of options. The paper provides one strategy for embedding higher order moments into the calculation of option prices, but alternative strategies also exist as well. Moreover, the paper shows the importance of pricing the risks of higher order moments to minimize the exposure of portfolios to price movements in market during financial crises. Whilst this analysis is conducted through the construction of delta-hedged portfolios, the analysis suggests the importance of expanding the set of Greek hedging parameters to include hedging strategies that explicitly take into account higher order moment behavior of returns, including Greeks that capture coskewness and cokurtosis.

\section{References}

[1] Aït-Sahalia, Y., Cacho-Diaz, J. and Laeven, R. (2010), "Modeling Financial Contagion Using Mutually Exciting Processes", NBER Working Paper No w15850.

[2] Aït-Sahalia, Y., Wang, Y. and Yared, F. (2001), "Do Option Markets Correctly Price the Probabilities of Movement of the Underlying Asset?", Journal of Econometrics, 102, 67-110.

[3] Ane, T. (1999), "Pricing and Hedging S\&P500 Options with Hermite Polynomial Approximation: Empirical Tests of Madan and Milne's Model", Journal of Futures Markets, 19, 735-758.

[4] Bae, K.H., Karolyi, G.A. and Stulz, R.M. (2003), “A New Approach to Measuring Financial Contagion", Review of Financial Studies, 16, 717-763.

[5] Boyle, P.P. (1977), "Options: A Monte Carlo Approach", Journal of Financial Economics, 4, 323-338. 
[6] Busetti, F and Harvey, A.C. (2011), "When is a Copula Constant? A Test for Changing Relationships", Journal of Financial Econometrics, 9, 106-131.

[7] Corrado, C.J. and Su, T. (1997), "Implied Volatility Skews and Stock Index Skewness and Kurtosis implied by S\&P 500 index Option Prices", Journal of Derivatives, Summer, 8-19.

[8] Cox J.C., and Ross, S.A. (1976), "The Valuation of Options for Alternative Stochastic Processes", Journal of Financial Economics, 3, 145-166.

[9] Cox, J.C., and Ross, S.A., Rubinstein, M. (1979), "Option Pricing: A Simplified Approach", Journal of Financial Economics, 7, 229-263.

[10] Cheang, G.H.L., and Chiarella, C. (2008), "Exchange Options under JumpDiffusion Dynamics", Quantitative Finance Research Centre, Research Paper No. 235.

[11] Diebold, F.X. and Yilmaz, K. (2009), "Measuring Financial Asset Return and Volatility Spillovers, with Applications to Global Equity Markets", Economic Journal, 119, 158-171.

[12] Dungey, M., Fry, R.A., González-Hermosillo, B. and Martin, V.L. (2010), Transmission of Financial Crises and Contagion: A Latent Factor Approach, Oxford University Press.

[13] Eichengreen, B., Rose, A. and Wyplosz, C. (1995), "Exchange Market Mayhem: The Antecedents and the Aftermath of Speculative Attacks", Economic Policy 10, $249-312$.

[14] Eichengreen, B., Rose, A. and Wyplosz, C. (1996), "Contagious Currency Crises: First Tests", Scandinavian Journal of Economics, 98, 463-484.

[15] Favero, C.A. and Giavazzi, F. (2002), "Is the International Propagation of Financial Shocks Non-linear? Evidence from the ERM", Journal of International Economics, 57, 231-246.

[16] Flynn, D.B., Grose, S.D., Martin, G.M. and Martin, V.L. (2005), "Pricing Australian S\&P200 Options: A Bayesian Approach Based on Generalized Distributional Forms", Australian and New Zealand Journal of Statistics, 47, 101-117.

[17] Frankel, J. and Rose, A. (1996), "Currency Crashes in Emerging Markets: An Empirical Treatment", Journal of International Economics, 41, 351-366. 
[18] Fry, R.A., Martin, V.L., and Tang, C. (2010), "A New Class of Tests of Contagion with Applications", Journal of Business and Economic Statistics, 28, 423-437.

[19] Fry-McKibbin, R.A., Martin, V.L., and Tang, C. (2013), "Financial Contagion and Asset Pricing", CAMA Working Paper \#61/2013.

[20] Garcia, R. and Gencay, R. (2000), "Pricing and Hedging Derivative Securities with Neural Networks and a Homogeneity Hint", Journal of Econometrics, 94, 93-115.

[21] Harvey, A.C. (2010), "Tracking a Changing Copula", Journal of Empirical Finance, 17, 485-500.

[22] Hull, J. (2000), Options, Futures and Other Derivatives, Upper Saddle River, NJ: Prentice-Hall, Fourth Edition.

[23] Jarrow, R. and Rudd, A. (1982), "Approximate Option Valuation for Arbitrary Stochastic Processes", Journal of Financial Economics, 10, 347-369.

[24] Kaminsky, G. and Reinhart, C.M. (1999), The Twin Crises: The Causes of Banking and Balance of Payments Problems", American Economic Review, 89, 473500 .

[25] Lim, G.C., Lye, J.N., Martin, G.M. and Martin, V.L. (1998), "The Distribution of Exchange Rate Returns and the Pricing of Currency Options", Journal of International Economics, 45, 351-368.

[26] Lim, G.C., Martin, G.M. and Martin, V.L. (2006), "Pricing Currency Options in the Presence of Time-Varying Volatility and Non-normalities", Journal of Multinational Financial Management, 16, 291-314.

[27] Lim, G.C., Martin, G.M. and Martin, V.L. (2005), "Parametric Pricing of Higher Order Moments in S\&P500 Options", Journal of Applied Econometrics, 20, 377404 .

[28] Lo Duca, M. and Peltonen, T.A. (2013), "Assessing Systemic Risks and Predicting Systemic Events", Journal of Banking and Finance, 37, 2183-95.

[29] Margrabe, W. (1978), "The Value of An Option to Exchange One Asset for Another", The Journal of Finance, 33, 177-186.

[30] Martin, V.L. and Wang, J. (2013), "A Conditional Copula Test of Contagion", mimeo. 
[31] Martin, G.M., Forbes, C.S. and Martin, V.L. (2005), "Implicit Bayesian Inference Using Option Prices", Journal of Time Series Analysis, 26, 437-462.

[32] Melick, W.R. and Thomas, C.P. (1997), "Recovering an Asset's Implied PDF from Option Prices: An Application to Crude Oil During the Gulf Crisis", Journal of Financial Quantitative Analysis, 32, 91-115.

[33] Patton, A. (2006), "Modelling Asymmetric Exchange Rate Dependence", International Economic Review, 47, 527-556.

[34] Pesaran, H. and Pick, A. (2007), "Econometric Issues in the Analysis of Contagion", Journal of Economic Dynamics and Control, 31, 1245-1277.

[35] Rodriguez, J.C. (2007), "Measuring Financial Contagion: A Copula Approach", Journal of Empirical Finance, 14, 401-423.

\section{A Appendix: Derivation of Deltas for An Exchange Option}

From equation (3), the price of a European exchange option at time $t$ to exchange asset 2 for asset 1 at time $T$, is

$$
C_{t}^{B S}=P_{1, t} \exp \left(-q_{1}(T-t)\right) N\left(d_{1}\right)-P_{2, t} \exp \left(-q_{2}(T-t)\right) N\left(d_{2}\right)
$$

where $P_{1, t}$ and $P_{2, t}$ are the underlying asset prices of assets 1 and 2 respectively, $q_{1}$ and $q_{2}$ are the respective dividend yields and

$$
\begin{gathered}
d_{1}=\frac{\ln \left(P_{1, t} / P_{2, t}\right)+\left(q_{2}-q_{1}+\sigma^{2} / 2\right)(T-t)}{\sigma \sqrt{(T-t)}} \\
d_{2}=d_{1}-\sigma \sqrt{T-t}
\end{gathered}
$$

with $N($.$) representing the cumulative probability density function of a variable that$ is normally distributed with zero mean and a standard deviation of one, and

$$
\sigma=\sqrt{\sigma_{1}^{2}+\sigma_{2}^{2}-2 \rho \sigma_{1} \sigma_{2}}
$$

where $\sigma_{1}$ and $\sigma_{2}$ are the volatility rates of assets 1 and 2 respectively and $\rho$ measures the correlation between the two assets.

The partial derivatives of $d_{1}$ and $d_{2}$ with respect to $P_{1, t}$ are

$$
\frac{\partial d_{1}}{\partial P_{1, t}}=\frac{1}{\sigma \sqrt{(T-t)}}\left(\frac{1}{\frac{1}{P_{2, t}} P_{1, t}}\right)\left(\frac{1}{P_{2, t}}\right)=\frac{1}{\sigma \sqrt{(T-t)} P_{1, t}}
$$


and

$$
\frac{\partial d_{2}}{\partial P_{1, t}}=\frac{1}{\sigma \sqrt{(T-t)} P_{1, t}}
$$

respectively. It follows that

$$
\frac{\partial d_{1}}{\partial P_{1, t}}=\frac{\partial d_{2}}{\partial P_{1, t}}
$$

Now, an expression which links $d_{1}^{2}$ and $d_{2}^{2}$ may be derived from equation (5), with $d_{1}$ in the second line of derivation below substituted by equation (4)

$$
\begin{aligned}
d_{2}^{2} & =\left(d_{1}-\sigma \sqrt{(T-t)}\right)^{2} \\
& =d_{1}^{2}+\sigma^{2}(T-t)-2 d_{1} \sigma \sqrt{(T-t)}, \\
& =d_{1}^{2}+\sigma^{2}(T-t)-2 \sigma\left[\frac{\ln \left(P_{1, t} / P_{2, t}\right)+\left(q_{2}-q_{1}+\sigma^{2} / 2\right)(T-t)}{\sigma \sqrt{(T-t)}}\right] \sqrt{(T-t)}, \\
& =d_{1}^{2}-2 \ln \left(P_{1, t} / P_{2, t}\right)-2\left(q_{2}-q_{1}\right)(T-t) .
\end{aligned}
$$

Using the relationship between $d_{1}^{2}$ and $d_{2}^{2}$, the relationship between the normal density functions of the variables $d_{1}$ and $d_{2}$ can be derived. The normal density functions of $d_{1}$ and $d_{2}$ are given by

$$
n\left(d_{1}\right)=\frac{1}{\sqrt{2 \pi}} \exp \left(-d_{1}^{2} / 2\right)
$$

and

$$
n\left(d_{2}\right)=\frac{1}{\sqrt{2 \pi}} \exp \left(-d_{2}^{2} / 2\right)
$$

respectively.

Substituting the expression linking $d_{1}^{2}$ and $d_{2}^{2}$ into equation (32) yields the following

$$
\begin{aligned}
n\left(d_{2}\right) & =\frac{1}{\sqrt{2 \pi}} \exp \left(\frac{-\left[d_{1}^{2}-2 \ln \left(P_{1, t} / P_{2, t}\right)-2\left(q_{2}-q_{1}\right)(T-t)\right]}{2}\right), \\
& =\frac{1}{\sqrt{2 \pi}} \exp \left(-d_{1}^{2} / 2\right) \exp \left[\ln \left(P_{1, t} / P_{2, t}\right)+\left(q_{2}-q_{1}\right)(T-t)\right]
\end{aligned}
$$

which is expressed simply as

$$
n\left(d_{2}\right)=n\left(d_{1}\right) \exp \left[\ln \left(P_{1, t} / P_{2, t}\right)+\left(q_{2}-q_{1}\right)(T-t)\right]
$$

using equation (31). Upon further algebraic simplification, the equation for $n\left(d_{2}\right)$ becomes

$$
n\left(d_{2}\right)=n\left(d_{1}\right)\left(P_{1, t} / P_{2, t}\right) \exp \left[\left(q_{2}-q_{1}\right)(T-t)\right]
$$


Partially differentiating the valuation equation for the exchange option with respect to $P_{1, t}$ yields

$$
\begin{aligned}
\frac{\partial C^{B S}}{\partial P_{1, t}}= & \exp \left(-q_{1}(T-t)\right) N\left(d_{1}\right)+P_{1, t} \exp \left(-q_{1}(T-t)\right) \frac{\partial N\left(d_{1}\right)}{\partial P_{1, t}} \\
& -P_{2, t} \exp \left(-q_{2}(T-t)\right) \frac{\partial N\left(d_{2}\right)}{\partial P_{1, t}} \\
= & \exp \left(-q_{1}(T-t)\right) N\left(d_{1}\right)+P_{1, t} \exp \left(-q_{1}(T-t)\right) n\left(d_{1}\right) \frac{\partial d_{1}}{\partial P_{1, t}} \\
& -P_{2, t} \exp \left(-q_{2}(T-t)\right) n\left(d_{2}\right) \frac{\partial d_{2}}{\partial P_{1, t}}
\end{aligned}
$$

Substituting out $n\left(d_{2}\right)$ and $\frac{\partial d_{2}}{\partial P_{1, t}}$ using equations (33) and (29) respectively yields

$$
\begin{aligned}
\frac{\partial C^{B S}}{\partial P_{1, t}}= & \exp \left(-q_{1}(T-t)\right) N\left(d_{1}\right)+P_{1, t} \exp \left(-q_{1}(T-t)\right) n\left(d_{1}\right) \frac{\partial d_{1}}{\partial P_{1, t}} \\
& -P_{2, t} \exp \left(-q_{2}(T-t)\right)\left\{n\left(d_{1}\right)\left(P_{1, t} / P_{2, t}\right) \exp \left[\left(q_{2}-q_{1}\right)(T-t)\right]\right\} \frac{\partial d_{1}}{\partial P_{1, t}},
\end{aligned}
$$

which ultimately simplifies to

$$
\frac{\partial C^{B S}}{\partial P_{1, t}}=\exp \left(-q_{1}(T-t)\right) N\left(d_{1}\right) .
$$

Equation (34) shows how the value of the exchange option varies with changes in the underlying asset value given by $P_{1, t}$. A similar expression can be derived which gives the sensitivity of the option value to changes in the other asset value given by $P_{2, t}$

$$
\begin{aligned}
\frac{\partial d_{1}}{\partial P_{2, t}} & =\frac{1}{\sigma \sqrt{(T-t)}}\left(\frac{1}{\frac{P_{1, t}}{P_{2, t}}}\right)\left(-\frac{P_{1, t}}{P_{2, t}^{2}}\right)=-\frac{1}{\sigma \sqrt{(T-t)} P_{2, t}} \\
\frac{\partial d_{2}}{\partial P_{2, t}} & =\frac{\partial d_{1}}{\partial P_{2, t}}=-\frac{1}{\sigma \sqrt{(T-t)} P_{2, t}}
\end{aligned}
$$

Using equations(31) and (30), an expression for $n\left(d_{1}\right)$ which provides a link to $n\left(d_{2}\right)$ is derived

$$
n\left(d_{1}\right)=n\left(d_{2}\right)\left(\frac{P_{2, t}}{P_{1, t}}\right) \exp \left[-\left(q_{2}-q_{1}\right)(T-t)\right] .
$$

Partially differentiating the valuation equation for the exchange option with respect 
to $P_{2, t}$ yields

$$
\begin{aligned}
\frac{\partial C^{B S}}{\partial P_{2, t}}= & P_{1, t} \exp \left(-q_{1}(T-t)\right) \frac{\partial N\left(d_{1}\right)}{\partial P_{2, t}} \\
& -\left[P_{2, t} \exp \left(-q_{2}(T-t)\right) \frac{\partial N\left(d_{2}\right)}{\partial P_{2, t}}+\exp \left(-q_{2}(T-t)\right) N\left(d_{2}\right)\right], \\
= & P_{1, t} \exp \left(-q_{1}(T-t)\right) n\left(d_{1}\right) \frac{\partial d_{1}}{\partial P_{2, t}} \\
& -P_{2, t} \exp \left(-q_{2}(T-t)\right) n\left(d_{2}\right) \frac{\partial d_{2}}{\partial P_{2, t}}-\exp \left(-q_{2}(T-t)\right) N\left(d_{2}\right) .
\end{aligned}
$$

Substituting out $n\left(d_{1}\right)$ and $\frac{\partial d_{1}}{\partial P_{1, t}}$ using equations (35) and (29) respectively yields

$$
\begin{aligned}
\frac{\partial C^{B S}}{\partial P_{2, t}}= & P_{1, t} \exp \left(-q_{1}(T-t)\right)\left[n\left(d_{2}\right)\left(\frac{P_{2, t}}{P_{1, t}}\right) \exp \left[-\left(q_{2}-q_{1}\right)(T-t)\right]\right] \frac{\partial d_{2}}{\partial P_{2, t}} \\
& -P_{2, t} \exp \left(-q_{2}(T-t)\right) n\left(d_{2}\right) \frac{\partial d_{2}}{\partial P_{2, t}}-\exp \left(-q_{2}(T-t)\right) N\left(d_{2}\right),
\end{aligned}
$$

which upon rearranging becomes

$$
\frac{\partial C^{B S}}{\partial P_{2, t}}=-\exp \left(-q_{2}(T-t)\right) N\left(d_{2}\right)
$$

Equation (36) provides the change in the exchange option value with respect to a change in the value of the other underlying asset $P_{2, t}$. 


\section{University Library}

\section{- M M I E E R VA A gateway to Melbourne's research publications}

Minerva Access is the Institutional Repository of The University of Melbourne

Author/s:

Fry-McKibbin, R;Martin, VL;Tang, C

Title:

Financial contagion and asset pricing

Date:

2014-10-01

Citation:

Fry-McKibbin, R., Martin, V. L. \& Tang, C. (2014). Financial contagion and asset pricing. JOURNAL OF BANKING \& FINANCE, 47, pp.296-308. https://doi.org/10.1016/ j.jbankfin.2014.05.002.

Persistent Link:

http://hdl.handle.net/11343/128252 